\title{
Presente: o tempo do jornalismo e seus desdobramentos
}

The Present: temporality in journalism and its consequences

\section{Edson Fernando DALMONTE}

Resumo: Discute a noção de temporalidade no campo do jornalismo. Partindo do princípio de que a atualidade é a base da narrativa jornalística, reflete acerca dos dispositivos empregados para dar densidade ao presente: o passado, como elemento da memória e o futuro, como projeção. Dessa forma, procura entender os modos a partir dos quais o jornalismo estabelece estratégias capazes de criar o sentido de "presentificação", simulando a ideia de atualidade, o que coloca num mesmo plano temporal o fato, sua narrativa e o leitor, embora, no geral, o relato jornalístico refira-se a algo já ocorrido.

Palavras-chave: História; Jornalismo; Narrativa

\begin{abstract}
This discussion is about the concept of temporality in the field of journalism, starting from the principle that current events are the basis of journalistic narrative reflecting two devices used to bring density to the present: the past, as a factor of memory, and the future as projection. In doing so, we intend to understand the ways in which journalism establishes strategies enabling the creation of the sense of "presentification", simulating the idea of a current event. At the same time it fits together the dimension of fact, its narrative and the reader, although, in general, the journalistic narrative refers to some event that has already happened.
\end{abstract}

Keywords: History; Journalism; Narrative.

Toda a tradição do jornalismo está assentada sobre concepções acerca da temporalidade, visto que o produto jornalístico deve possibilitar ao leitor participar de um presente amplo, global, capaz de coincidir com o seu. Para operacionalizar uma descrição da temporalidade no jornalismo, Franciscato (2005, p.112-162) propõe cinco categorias descritivas desses fenômenos que, para o autor, alcançam objetividade social, a saber: 1) instantaneidade; 2) simultaneidade; 3) periodicidade; 4) novidade; 5) revelação pública.

A ideia da instantaneidade reforça o papel da importância do presente, ou melhor, do instante. “O 'instante' é aplicado para qualificar um período de tempo muito curto, que parece não ter uma duração significativa que nos possibilitaria perceber a passagem do tempo." (FRANCISCATO, 2005, p.113). Para o autor, a referida situação poderia conduzir a uma predominância da temporalidade do presente, do 'agora'. "Os termos 'instantâneo' e 'instantaneidade' surgem para reforçar e qualificar tanto o sentido de imediatez ou rapidez de uma ação quanto de veiculação de um intervalo ínfimo de tempo (ou de sua virtual inexistência) ao momento presente.” (FRANCISCATO, 2005, p.113-114).

Por simultaneidade "pode ser preliminarmente entendido como o que ocorre o é feito ao

\footnotetext{
- Professor Doutor - Departamento de Comunicação e do Programa de Pós-Graduação em Cultura Contemporânea UFBA - Univ. Federal da Bahia - Rua Barão de Jeremoabo, s/n, CEP: 40170-115, Salvador, Bahia, Brasil. E-mail: edsondalmonte@,uol.com.br
} 
mesmo tempo ou quase ao mesmo tempo que outra coisa." (FRANCISCATO, 2005, p.124). Há, com isso, o desenvolvimento de uma ideia de não haver distinção entre os tempos da narrativa e o das coisas, pois "o jornalismo constrói um discurso e uma prática que tem, por exemplo, a instantaneidade como estratégia de legitimação, valor e fím último.” (p.134).

Ao situar periodicidade, o autor põe em relevo a capacidade de produção e circulação do material jornalístico, a partir de uma demanda social de acompanhar o desenrolar dos fatos. Para tanto, segundo Franciscato, “a noção de periodicidade implica em percebermos um aspecto específico que será fundamental ao jornalismo: o surgimento de uma necessidade social de que a sociedade fosse abastecida por notícias em períodos regulares e com intervalos mais curtos." (p.137-138).

A novidade está na gênese da narrativa jornalística, tendo-se em vista o apelo que o "novo" tem para operacionalizar mecanismos por meio dos quais possa irromper o desconhecido na ordem do dia.

Afirmar a novidade como termo fundamental no jornalismo significa dizer que a notícia surge historicamente para dar conta da tarefa de prover a sociedade com um relato padronizado sobre novas ações, situações, debates e opiniões, entre outros, que tenham relevância para uma coletividade (FRANCISCATO, 2005, p.147).

Por fim, dentre as categorias definidas por Franciscato (2005), está a revelação pública. Por meio desta noção, é explicitada uma dimensão relevante do presente jornalístico. Na condição de narrativa que irrompe na ordem do dia, o jornalismo pode tanto oferecer o novo como, por meio da revelação, trazer a público fatos ocorridos e mantidos em sigilo. Tem-se, desta forma, a atualização, pois " $[\mathrm{os}$ fatos] tornam-se atuais no momento em que o exercício jornalístico de investigação desfaz barreiras de 'segredo' e veicula esses conteúdos para informação e debate público. Este ato jornalístico pode ser denominado “revelação." (FRANCISCATO, 2005, p.159).

O jornalismo assume, com isso, o papel de articular o presente, de aproximar o leitor dos fatos que, sob a perspectiva dos critérios de noticiabilidade, ${ }^{1}$ merecem passar à categoria de notícia. O presente pretendido pelo jornalismo, pode-se dizer, não é apenas o momento do acontecimento, que se pressupõe transportável para perto do destinatário, mas o momento da apresentação, ou revelação pública, como sugere Franciscato. Por meio da revelação, vai-se além da rememoração de um ocorrido, mas dá-se a forma, são traçados os contornos de um acontecimento, ele ganha cor e profundidade; articula-se à vida do destinatário que, por sua vez, se vê ligado ao mundo que o circunda.

Cada organização discursiva adota estratégias para assegurar o efeito de real, ${ }^{2}$ isto é, para conferir a si uma legitimidade. Com o discurso jornalístico, da mesma forma, ao longo de sua consolidação, observa-se que vários elementos buscam assegurar coerência à narrativa, centrada na 
divulgação de fatos vistos como relevantes para o cotidiano. A valorização dos acontecimentos e sua seleção estão situados entre os elementos que aferem o sentido de veracidade aos fatos reportados pela mídia. A apresentação do real é a condição necessária que justifica a existência do jornalismo. É importante ressaltar que tem havido divergência quanto a essa capacidade, ora vista como absoluta, ${ }^{3}$ ora com parcimônia, uma vez que todo relato constitui uma versão dos fatos. Mediante tais questionamentos, cumpre ressaltar que os objetivos do presente artigo dizem respeito à relevância das noções de temporalidade para a construção do relato jornalístico.

\section{Passado e futuro como dimensões do presente}

Para que se entenda o plano dos relatos jornalísticos, há que se compreender a organização discursiva como articuladora de temporalidades, incluindo-se o ontem, o hoje e o amanhã como dimensões necessárias à formação daquilo que se chama acontecimento. A ambiguidade da narrativa jornalística no que tange ao tempo, ou melhor, à temporalidade do presente, pode ser observada pela opção de uso do tempo verbal do presente do indicativo, independentemente de o fato estar em processo ou de já ter ocorrido, o que justificaria o emprego do passado simples. O uso do tempo presente justifica-se pela necessidade de simular a presença do leitor na cena na qual se desenrolaram os fatos. Dessa forma, abundam, no discurso jornalístico, expressões como morre, nasce, sobe, muda etc. Por intermédio desse artifício, tem-se a ideia de que o fato ainda acontece, que o leitor está ligado a ele. Estamos todos, leitores e narradores, naquela cena, ainda sendo tocados por aquela ação.

O passado, por seu turno, marca o fim, a conclusão de um fato, o que pode promover um efeito de sentido de distanciamento entre o indivíduo e o mundo. Verbos no passado, como acabou, morreu etc., podem conduzir a uma leitura que marca o fim de um ciclo. Como exemplo, a capa da Folha da Manhã, do dia 06 de Março de 1953, que traz como título principal: "Morreu Stalin”. Por meio desse título, não é anunciada apenas a morte de Stalin, mas se apresenta também o desejo do mundo capitalista de que finde a União Soviética. A exemplo disso, uma chamada menor: "O fim de uma existência extremamente agitada", e o texto que se segue: "Preso e deportado numerosas vezes, Stalin desenvolveu grande atividade nas lutas revolucionárias em que se empenharam os marxistas."

Outra página, com a mesma proposta temporal, aparece em 03 de Janeiro de 1959, também na Folha da Manhã, trazendo chamada igualmente no passado, relativa à União Soviética: "Rádio de Moscou: A U.R.S.S. lançou foguete à lua.” Da mesma forma que no exemplo precedente, o enunciado traz a ideia de uma ação realizada. No contexto da Guerra Fria e como consequente polarização entre Estados Unidos e União Soviética, a notícia de mais um lançamento dessa 
importância, ${ }^{4}$ seguramente, diz respeito a um conjunto de expectativas sociais em relação ao ocorrido. Contudo, o enunciado é atribuído à Rádio de Moscou; a afirmação é feita por ela.

Estes dois exemplos de uso raro do passado nos enunciados jornalísticos, todavia, apenas ilustram a preponderância do uso do tempo presente nessas narrativas. A formação discursiva deve ser entendida como fazendo parte de uma conjuntura histórica, o que pode explicar determinados posicionamentos, como a escolha de tempos verbais. Num exemplo mais recente, a morte do papa João Paulo II é noticiada com o uso do presente do indicativo: "Papa João Paulo $2^{\circ}$ morre aos 84 anos em Roma". No título, a morte do papa está "presentificada", pois ela terá grandes repercussões, como num ciclo que apenas se fechou com a escolha do sucessor do Vaticano, dias depois. Contudo, logo na abertura, o texto usa o pretérito-perfeito do indicativo:

Karol Josef Wojtyla, o papa João Paulo $2^{\circ}$, morreu neste sábado, aos 84 anos em Roma, após dois dias de agonia. Comunicado oficial do Vaticano informa que o sumo pontífice morreu às $21 \mathrm{~h} 37$ [16h37 de Brasília] do dia 2 de Abril de $2005 \mathrm{em}$ seus aposentos no Palácio Apostólico (grifos nossos).

São várias as tradições que têm se dedicado a estudar as dimensões da temporalidade. Mais especificamente, a duração do instante, a extensão do presente. Estudiosos da Filosofia, Física e Matemática, por exemplo, têm demonstrado especial atenção à "profundidade" do presente, às formas de permanência do atual ou da fluidez do instante. ${ }^{5}$ Para as questões pertinentes a este trabalho, serão analisadas contribuições na perspectiva da Análise do Discurso, considerando-se o aspecto temporal como elemento relevante para a proposição e a construção de sentido.

Considerando-se o discurso jornalístico (compreendendo-se as várias modalidades textuais) como uma narrativa, ${ }^{6}$ a perspectiva temporal torna-se uma importante variável para que se entenda o posicionamento deste discurso na sociedade, bem como seu impacto na organização da vida das pessoas.

O mundo exibido por qualquer obra narrativa é sempre um mundo temporal [...] o tempo torna-se tempo humano na medida em que está articulado de modo narrativo; em compreensão, a narrativa significativa na medida em que esboça os traços da experiência temporal (RICOEUR, 1994, p.15).

Com o intuito de entender o impacto da perspectiva temporal da narrativa, Paul Ricoeur, em Tempo e Narrativa (1994), busca articular as ideias presentes em Poética, de Aristóteles (2000), ${ }^{7}$ e Confissões, de Santo Agostinho (2006). ${ }^{8}$ Na perspectiva da Análise do Discurso, o cruzamento de tais obras permite situar o plano narrativo dentro de uma temporalidade mais ampla, passando pelo passado, presente e pelas projeções do porvir. É sobre este cenário que se inscreve a história de todos os indivíduos. 
Como preâmbulo às ideias de Agostinho, pode-se tomar seu questionamento sobre a temporalidade: “o que é realmente o tempo?” (2006, p.338). Para as indagações do autor, que na lógica da fenomenologia questiona-se acerca dos mistérios do homem frente ao eterno, entender o que é o tempo torna-se basilar, pois o percurso da humanidade só tem sentido no aqui e agora, tomando-se por referência o que já foi e o que será.

Posso dizer com segurança que não existiria um tempo passado, se nada passasse; e não existiria um tempo futuro, se nada devesse vir; e não haveria o tempo presente se nada existisse. De que modo existem esses dois tempos - passado e futuro -, uma vez que o passado não mais existe e o futuro ainda não existe? E quanto ao presente, se permanecesse sempre presente não se tornasse passado, não seria mais tempo, mas eternidade. Portanto se o presente, para ser tempo, deve tornar-se passado, como poderemos dizer que existe, uma vez que a sua razão de ser é a mesma pela qual deixará de existir (AGOSTINHO, 2006, p.338-339).

O que interessa, neste sentido, é a transitoriedade do tempo: o passado como o presente que se esgota; o futuro como a projeção que se faz a partir do aqui e agora do instante atual, cabendo ao presente a posição central entre passado e futuro. O que permite ao presente recuperar o passado e projetar o futuro é uma articulação entre a linguagem e a memória, o que dá forma ao discurso. Sobre essa relação, diz Ricoeur (1994, p.23):

Agostinho vai, primeiro, parecer dar as costas à certeza de que é o passado e o futuro que se medem. Ulteriormente, colocando o passado e o futuro no presente, por intermédio da memória e da espera, poderá salvar esta certeza inicial de um desastre aparente, transferindo para a espera e para a memória a idéia de um longo futuro e de um longo passado. Mas esta certeza da linguagem, da experiência e da ação só será recuperada depois de ter sido perdida e profundamente transformada.

Apontando como umas das possibilidades do ato poético o plano narrativo, Aristóteles diz que "poesia é imitação". Para o autor, "diferem [os tipos de narrativa], porém umas das outras, por três aspectos: ou porque imitam por meios diversos, ou porque imitam objectos diversos, ou porque imitam por modos diversos e não da mesma forma." (2000, p.103).

A imitação, na narrativa, refere-se ao ato de selecionar os elementos linguísticos que irão compor o fato reportado. Como sugere Aristóteles (2000, p.103),

pois tal como há os que imitam muitas coisas, exprimindo-se com cores e figuras [...], assim acontece nas sobreditas artes: na verdade, todas elas imitam com o ritmo, a linguagem e a harmonia, usando estes elementos separada ou conjuntamente.

É interessante ressaltar que aquilo que nós compreendemos usualmente como narrativa é o que Aristóteles chama de simples narrativa ou narrativa mista. Ele se atém ao drama, que considera 
a mais perfeita forma de relatar um fato, como se nota na afirmação seguinte:

É, pois, a tragédia imitação de uma acção de caráter elevado, completa e de certa extensão, em linguagem ornamentada e com as várias espécies de ornamentos distribuídas pelas diversas partes do drama, imitação que se efectua não por narrativa, mas mediante actores, e que, suscitando o terror e a piedade, tem por feito a purificação dessas emoções (ARISTÓTELES, 2000, p.110, grifo do autor).

Dessa forma, para Aristóteles, é por meio da dramatização, da possibilidade de confronto, do diálogo eloquente, do uso de artifícios, que uma história pode ser contada com mais propriedade. Falando da imitação narrativa e em verso, diz o autor que o mito aí relatado deve ser estruturado segundo a forma dramática, como na tragédia. Da mesma forma, para o autor, é preciso respeitar a ideia de completude da ação, ou seja, apresentar início, meio e fim, o que faz pensar na importância de situar o tempo, para a significação daquilo que se conta. (ARISTÓTELES, 2000, p.138).

Fiorin (2002, p.130) diz que aquilo que não é, no caso, o tempo em sua transitoriedade, é corporificado por meio da linguagem. Com base em Agostinho, afirma que "dizemos a respeito do passado que foi longo [...] e do futuro que será longo.” Por meio da língua, e de suas estratégias corporificadas no discurso, é que o tempo pode ser vivenciado.

Nessa perspectiva, a narrativa se constitui no ato da imitação da realidade. Segundo Aristóteles (2000, p.106-107), “o imitar é congênito no homem (e nisso difere dos outros viventes, pois, de todos, é ele o mais imitador e, por imitação, apreende as primeiras noções), e os homens se comprazem no imitado." É por meio da língua que o narrador se posiciona em relação ao fato narrado; o fato reportado assemelha-se ao real, na qualidade de imitação.

Como pode, então, ser concebido o tempo? Em especial, é possível falar de presente? Para Agostinho (2006, p.341), "se pudermos conceber um espaço de tempo que não seja susceptível de ser dividido em minúsculas partes de momentos, só a este podemos chamar tempo presente". Seguindo os questionamentos do autor, não dá para falar que o ano corrente seja presente, pois ele está dividido em meses, e estes, em semanas, em dias. O dia de hoje, da mesma forma, encontra-se subdividido em horas, que não são vividas todas ao mesmo tempo. A possibilidade de redução a frações menores persiste, pois, das horas aos minutos e assim por diante. Presente é aquilo que se vive agora; o que vem antes é passado; aquilo que vem depois do futuro. "Esse [presente], porém passa tão velozmente do futuro ao passado, que não tem nenhuma duração. Se tivesse alguma duração, dividir-se-ia em passado e futuro.” (AGOSTINHO, 2006, p.341). A questão central reside na ausência de duração do presente: "logo, o tempo presente não tem nenhuma duração. Onde se encontra então o tempo que possa ser chamado de longo? O futuro? Não dizemos certamente que é longo, porque não existe ainda. Dizemos, sim, que será longo.” (AGOSTINHO, 2006, p.341). De maneira enfática, afirma Agostinho (2006, p.341): “o presente clama que não pode ser longo.” Mais 
uma vez, a ênfase está na fluidez do tempo, permanecendo a indagação acerca do presente, pois, se ele não tem extensão, como pode ser narrado?

As outras dimensões do tempo, passado e futuro, da mesma maneira que o presente, encontram-se inquiridas pela ausência de uma duração a qual possa ser medida, tangenciada. "Mas quem pode medir o tempo passado, que agora já não existe, ou o tempo futuro, que ainda não existe, se não tiver a coragem de dizer que pode medir o que não existe?” (AGOSTINHO, 2006, p.341342). A questão diz respeito do não ser do passado e do futuro.

Aos poucos, Agostinho (2006, p.344) conclui não ser possível falar de três tempos, isoladamente:

Agora está claro e evidente para mim que o futuro e o passado não existem, e que não é exato falar de três tempos - passado, presente e futuro. Seria talvez mais justo dizer que os tempos são três, isto é, o presente dos fatos passados, o presente dos fatos presentes, o presente dos fatos futuros.

Essa é a proposta de Agostinho, uma temporalidade trina, ${ }^{9}$ pois o passado não é algo extinto, ele é apenas o presente que se esgotou, mas que a todo instante é convocado a contribuir para que se entenda o presente, ou seja, o passado é a dimensão presente das coisas passadas. O presente das coisas futuras é a antecipação, que se articula no presente. Por meio da antecipação, o presente se projeta para o futuro. O presente das coisas presentes só é possível graças à articulação com o passado e com o futuro.

Sobre a relação trina do presente, Agostinho (2006, p.344-345) continua dizendo que "o presente do passado é a memória. O presente do presente é a visão. O presente do futuro é a espera. [...] o futuro não existe agora, nem o passado.” Segundo esta assertiva, apenas no nível do discurso é que o passado é rememorado e o futuro projetado. De acordo com a concepção aristotélica, a arte da imitação torna esta presentificação possível.

A dimensão temporal, para Genette (1995, p.214-215), assume caráter determinante numa narrativa, em detrimento de aspectos espaciais, vistos como secundários. Para o autor, é possível contar uma história sem detalhar o local no qual ela se passa, mas é determinante que o fato seja situado no tempo, em relação ao ato narrativo, visto que deve ser estabelecido a partir do presente, do passado ou do futuro. Tem-se, dessa forma, a pertinência da temporalidade no tocante ao ato de narrar, que há tempos vem demonstrando não caber à narrativa apenas uma posição em relação à história, elencando fatos após sua ocorrência. Fator importante para o estabelecimento de um plano narrativo focado na temporalidade é a capacidade de antecipação de uma ocorrência, que o autor apresenta como narrativa "predictiva".

Narrar, na perspectiva temporal, é falar sobre o que já não existe ou ainda não existe. Para Ricoeur (1994, p. 26), 
estamos, com efeito, prontos a considerar como seres não o passado e o futuro como tais, mas qualidades temporais que podem existir no presente sem que as coisas de que falamos quando as narramos ou as predizemos ainda existam ou já existam. Deveríamos, pois estar muitos atentos às transições de Agostinho.

O lugar ocupado pela narrativa e, por conseguinte, pelo narrador, diz respeito àquilo que é possível dizer sobre o tempo, em sua indissociável relação com o passado e o futuro. Ao presente cabe a possibilidade de ser "o lugar" desde onde se estabelece uma narrativa sobre o que passou e aquilo que virá.

Quanto ao presente, como o podemos medir, se não tem extensão? Nós o medimos enquanto ele passa [...] Donde então vem ele, por onde passa e para onde vai? Não pode vir senão do futuro, não pode passar senão pelo presente, e não pode acabar senão no passado. Provém daquilo que ainda não existe, atravessa o que não tem dimensão, para mergulhar no que já não existe. Todavia, o que medimos nós, senão o tempo tomado no espaço? (AGOSTINHO, 2006, p.345).

Entre o passado e o futuro, quais seriam os vínculos possíveis para o estabelecimento do plano narrativo? Para Agostinho (2006, p.355), a possibilidade advém de uma polarização entre a memória e a espera:

Quem se atreve a negar que o futuro ainda não existe? No entanto, já existe no espírito a expectativa do futuro. Quem pode negar que o passado não mais existe? Contudo, existe ainda no espírito a lembrança do passado. E quem nega que o presente carece de extensão, uma vez que passa em um instante? [...] Portanto, não é o futuro que é longo, pois não existe, mas o longo futuro é a espera do futuro. Também não é longo o tempo passado inexistente, mas o longo passado é a longa recordação do passado.

A narrativa, desse modo, tem como base a memória, pela necessidade de recuperar os fatos já ocorridos, e a previsão, relativa à capacidade de antecipar o que virá. Como lembra Ricoeur (1994, p.27), "narração, diremos, implica memória e previsão espera." O autor se questiona sobre o que vem a ser o recordar e define este ato como "ter uma imagem do passado." Se é passado, como seria possível essa permanência? "Porque essa imagem é uma impressão deixada pelos acontecimentos e que permanece fixada no espírito."

Sobre a previsão, Ricoeur (1994, p.27) aborda a importância da espera e de seu papel antecipador:

É graças a uma espera presente que as coisas futuras estão presentes a nós como porvir [...] A espera é assim análoga à memória. Consiste numa imagem que já existe no sentido de que precede o evento que ainda não é [...]; mas essa imagem ainda não é uma impressão deixada pelas coisas passadas, mas um "sinal" e uma "causa" das coisas futuras que assim são antecipadas, pré-percebidas, anunciadas, preditas, proclamadas antecipadamente. 
Tem-se, dessa forma, que o presente assume importante papel de articulador da temporalidade. A ele cabe tornar presente o que se passou, por meio da memória; e no hoje, presentificar, por meio da antecipação, o porvir. Entre o rememorar e o antecipar, articula-se a narrativa do presente. Pois, segundo Ricoeur (1994, p. 28),

confiando à memória o destino das coisas passadas e à espera das coisas futuras, pode-se incluir memória e espera num presente ampliado e dialetizado que não é nenhum dos termos anteriormente rejeitados: nem o passado, nem o futuro, nem o presente pontual, nem mesmo a passagem do presente.

Para Fiorin (2002), a partir do momento em que Agostinho centra seus questionamentos, por exemplo, nas imagens antecipantes, ele muda seu interesse do tempo físico e encaminha-se para reflexões acerca do tempo linguístico. Como sugere o autor: “a linguagem não somente é a prova de que o argumento cético não subsiste, mas também é o que propicia ao homem a experiência temporal, na medida em que só quando o tempo é semiotizado pode o ser humano apreendê-lo e medi-lo." (p.139).

\section{O triplo presente da narrativa jornalística}

Tomando por referência as reflexões propostas por Ricoeur (1994), Garcin-Marrou (1996) realiza um estudo sobre o modo como o jornalismo realiza a representação do acontecimento. De maneira específica, a autora busca entender a importância da perspectiva temporal para a organização e apresentação do discurso jornalístico, o que implica refletir sobre o que vem a ser a atualidade na narrativa jornalística.

De início, para Garcin-Marrou, é preciso que se entenda o evento como

se inscrevendo sobre uma memória social, política e histórica: esta [história], desempenha um papel para a compreensão e a designação do próprio acontecimento. Este [acontecimento], não surge num vazio histórico; ele se articula a um passado que tem uma carga de significações e que dá forma a sua percepção atual (1996, p.49).

Na proposta da autora, a percepção do acontecimento não pode acontecer de maneira isolada, como se o fato despontasse num dado momento, desconectado de todo o contexto. Se o fato é resultante de um processo histórico, da mesma forma, sua percepção também o é.

Garcin-Marrou (1996) afirma que a inscrição do acontecimento num fundo histórico apresenta dois problemas. Por um lado, a narrativa de um fato implica entender o processo por meio do qual um acontecimento passa à categoria de informação. Por outro lado, como se dá a atribuição de valor 
a um acontecimento, o que faz um fato sair do fluxo informativo e passar à categoria de acontecimento. "Quando um acontecimento aparece como tal na primeira página de um jornal, a estruturação de seu relato e a atribuição de seu valor já foram efetuadas, de modo quase simultâneo." (GARCIN-MARROU, 1996, p.49).

A inscrição de um acontecimento em uma memória, segundo Garcin-Marrou (1996, p.49), confere a ele uma estrutura temporal específica, pois: 'acontecimento não é apenas um 'surgimento' na atualidade; sua definição articula as dimensões do passado, do presente e do futuro.” O objetivo da autora é verificar como se articula a estrutura temporal no texto jornalístico, especificamente na cobertura sobre a Irlanda do Norte, ${ }^{10}$ sendo que o texto, na concepção da autora, é o resultado de um tensionamento entre a história e atualidade.

Para que se proceda a passagem de um fato à categoria de informação ou o relato do acontecido, o narrador deve, antecipadamente, ter identificado suas circunstâncias, duração, atores etc. Para tanto,

o narrador deve controlar aquilo que chamaremos, para retomar os termos de Paul Ricoeur, as 'estruturas de inteligibilidade' [o que permite compreender o fato como referenciável] o jornalista deve, para isso, conhecer a situação social e política na qual se produziu o acontecimento [...] esta situação está intimamente ligada à história e à memória (GARCIN-MARROU, 1996, p.50).

A menção que a autora faz a Ricoeur (1994) refere-se ao tecer da intriga, visto que ele só será possível a partir de um conhecimento íntimo dos fatos envolvidos, bem como da capacidade de articulação desses fatos uns com os outros. A tessitura da intriga, ou o agenciamento dos fatos, é uma reflexão de Ricoeur baseada em Aristóteles (2000) e seu conceito de imitação da realidade, ou mimese.

Como descreve Aristóteles (2000):

O poeta é imitador, como o pintor ou qualquer outro imaginário; por isso, sua imitação incidirá num destes três objectos: coisas quais eram ou quais são, quais os outros dizem que são ou quais parecem, ou quais deveriam ser. Tais coisas, porém, ele as representa mediante uma elocução que compreende palavras estrangeiras e metáforas e que, além disso, comporta múltiplas alterações, que efectivamente consentimos ao poeta (p.143, grifos nossos).

A realidade das coisas, passadas, presentes e futuras (imaginadas), aparece na organização da narrativa como base para que se entenda o processo de mimese que, para Ricoeur (1994), está dividido em três: mimese I, mimese II e mimese III. Entendendo-se a mimese como a imitação ou a representação da ação, diz Ricoeur (1994, p.60) que "a imitação ou a representação é uma atividade mimética enquanto produz algo, a saber, precisamente a disposição dos fatos pela tessitura da 
intriga."

No conjunto das três mimeses, ${ }^{11}$ o que interessa aqui é a segunda mimese, ou a configuração, por ela ter uma posição intermediária, desempenhando uma função de mediação (RICOEUR, 1994, p.102), ocupando papel determinante entre a primeira mimese, a prefiguração (que acontece no âmbito do enunciador) e a refiguração (junto à instância destinatária). A posição central diz respeito à organização textual propriamente dita, seguindo-se a lógica aristotélica, na qual a narrativa prevê o agenciamento dos fatos. Por meio da ação criativa, o mundo toma forma; ele é configurado.

Ricoeur (1994, p.103) aponta três motivos que tornam a intriga mediadora: inicialmente ela realiza uma ação de intermédio entre os fatos individualizados e uma narrativa tida como completa. Deste ato mediador, a partir de um contexto plural, ou uma simples sucessão de eventos, é retirada uma história vista como sensata, ressaltada desde um caráter unificador, tornando-a uma narrativa. A tessitura da intriga aí é vista como a mediação entre acontecimentos e história narrada, sendo uma operação criativa, capaz de extrair a configuração de uma simples sucessão de eventos.

Num segundo momento, surge a necessidade de que aconteça a integração coerente da narrativa, advinda da realidade de a intriga estar aberta para abarcar os vários incidentes, como os lamentáveis, os aterrorizantes, o reconhecimento daquilo que se negligenciava, etc. A junção de tais elementos deve assumir um caráter integrador, tendo-se em vista a necessidade de que a narrativa seja inteligível, fazendo com que seja mediadora entre os acontecimentos e a história contada, pois, como lembra Ferreira (1999, p.88), "uma história contada é mais do que uma enumeração ou uma sucessão de eventos."

A intriga é mediadora ainda por uma terceira razão, referente aos seus caracteres temporais próprios, basilares para a dinâmica constitutiva da narrativa (RICOEUR, 1994, p.104). Para a consolidação do plano narrativo e a tessitura da intriga, combinam-se, em diferentes proporções, duas dimensões temporais, uma cronológica e outra não-cronológica. A cronológica refere-se à dimensão episódica, caracterizando a história como sendo constituída por acontecimentos. A dimensão não-cronológica é a configurante, permitindo a transformação dos acontecimentos em história. Pelo ato configurante, põe-se em relação os "incidentes da história" e, a partir da diversidade de ocorrências, retira-se a unidade de uma totalidade temporal, que passa a ser o tempo da narrativa, ou o tempo narrado, com elemento unificador do plano narrativo, ou o tempo semiotizado.

Quanto ao discurso jornalístico, segundo Garcin-Marrou (1996, p.50), para que um fato possa passar de acontecimento a informação, o jornalista deve dominar o contexto sócio-político, pois o simples fato de saber o que aconteceu não lhe dá sustentação para a tessitura da intriga. É nesse sentido que a mimese II, ou a configuração, ganha importância, pois permite reunir os fatos, que, num primeiro olhar, podem parecer isolados, mas lhes confere uma unicidade narrativa. Conforme 
diz Aristóteles (2000, p.138), a imitação narrativa deve ser constituída "por uma ação inteira e completa, com princípio, meio e fim, para que, una e completa, qual organismo vivente, venha a produzir o prazer que lhe é próprio."

Com o intuito de estabelecer critérios quanto ao planto narrativo, Aristóteles (2000, p.139) afirma que as narrativas históricas não devem estar preocupadas com a exposição de uma ação única, mas sim de um tempo único, elencando-se os eventos ocorridos aos personagens aí envolvidos. O tempo surge como elemento agregador, segundo o plano narrativo, pois os eventos relacionam-se uns com os outros apenas casualmente.

É nesse sentido que Garcin-Marrou (1996, p.52-53) chama atenção sobre a relevância da memória histórica para a organização do plano discursivo do jornalismo, pois os relatos informativos tomam forma num contexto histórico. Se, para a conformação da intriga, é necessário lançar raízes no passado, da mesma forma, o relato do acontecimento pressupõe o entendimento do presente. É pela articulação passado-presente que a narrativa pode ser conformada, pois o relato do presente, do que se passa agora, a todo instante se remete (e nos remete) ao passado, o que faz pensar que o surgimento do acontecimento não é a única dimensão temporal posta em marcha no campo da informação.

As reflexões de Agostinho (2006), retomadas por Ricoeur (1994), centradas no triplo presente, a saber: o presente das coisas passadas, o presente das coisas presentes e o presente das coisas futuras, constituem-se base da narrativa jornalística. O presente das coisas passadas refere-se à concepção histórica, que, em sentido amplo, deve ser revisitada, pois é a historicidade dos fatos que agrega sentido, atualizando o ocorrido, que pode ser apresentado e reinvestido de significados. O presente das coisas presentes é o fato enquanto tal; é o anúncio ou apresentação de um acontecimento. $\mathrm{O}$ presente das coisas futuras refere-se à influência no porvir que o acontecimento narrado pode fazer ressoar. O evento narrado é capaz de antecipar realidades, que podem ou não se concretizar, mas a ideia da previsibilidade lança o leitor num movimento de espera, com base nas expectativas apresentadas.

Se o tempo do jornalismo é o presente, o agora, que coloca ocorrido e leitor num mesmo cenário, é inegável que, a todo o momento, este presente presentifica fatos passados, determinantes para a fundamentação daquilo que se apresenta como surgindo no instante atual. Quando considerada a perspectiva contratual da comunicação, na qual se valoriza "aquilo que surge agora", pode-se, por equívoco reducionista, interpretar tal constatação como a preponderância do atualismo. No entanto, o discurso, ao lançar suas bases no passado, confere profundidade aos fatos, o que dá densidade ao presente. Da mesma forma, o presente densificado pela perspectiva histórica prolongase sobre o futuro, conferindo ao atual também a dimensão futura, fazendo que, por meio do fato apresentado, o leitor transite do passado ao futuro, tornado próximo à medida que as expectativas 
dizem respeito a projeções estabelecidas a partir do agora.

O tempo do relato jornalístico é o atual, aquilo que está na ordem do dia, mas, segundo o plano narrativo, o agenciamento dos fatos é determinante para a articulação dos tempos. Dessa feita, assume-se que o triplo presente é o tempo do relato jornalístico por excelência. A noção de temporalidade trina permite que o acontecimento se torne inteligível, e o leitor se veja incluído não num simples relato, mas num planto narrativo, compreendendo-se passado, presente e futuro. A questão daí advinda diz respeito às estratégias usadas pela mídia para apresentar ao leitor o plano narrativo, assentado num presente trino e nas possibilidades de criar, junto ao leitor, a crença de estar sobre a cena que se desenrola e diz respeito a sua vida.

Sobre os novos formatos jornalísticos, Fechine (2008, p. 162) chama a atenção para o fato de que o telejornalismo, por meio da inserção de participações "ao vivo" de repórteres, convocados pelos apresentadores, propõe estabelecer uma "concomitância temporal." Observa-se, segundo a autora, que apresentador e repórter estão situados no mesmo agora da enunciação e do conteúdo que se enuncia. Chega-se a tal formato com a ajuda de aparatos tecnológicos como helicópteros, que transportam repórter e cinegrafista para cobrir um evento, permitindo que a partir de um mesmo lugar se capte diferentes ângulos do objeto em questão.

A dimensão temporal é também um importante fator na organização do discurso que se desenvolve no ambiente Web, como no Webjornalismo, ou jornalismo digital. A grande promessa gira em torno da possibilidade de oferta de notícias em tempo real. De maneira precursora, o rádio, seguido da televisão, conseguiu romper com a noção de periodicidade rígida, como é o caso do impresso, e apresentar fatos considerados relevantes fora de sua grade de programação. Importante inovação acontece com a Internet, que permite a divulgação a qualquer instante e a permanência do conteúdo, para acesso posterior, via base de dados.

Os Webjornais adotam slogans que afirmam a posição de produtores e divulgadores de notícias ininterruptamente. Exemplo do slogan-promessa, o Último Segundo ${ }^{12}$ (criado em 2000) traz: "Notícias de economia, política, esportes e cultura em tempo real." Como ressalta Santos (2002, p.88), a proposta era a disponibilização de uma nova notícia a cada noventa segundos. Por vezes, o intervalo era menor, chegando a publicar cerca de mil por dia. ${ }^{13}$

O Globo Online apresenta "Plantão", onde são disponibilizadas notícias a cada minuto, em média, em editorias. Além do material disponibilizado via site, é possível ter acesso remoto ao material: "Que assunto mais interessa a você? Qual o seu blog preferido? Através do RSS $^{14}$ você tem acesso direto ao conteúdo que escolher atualizado automaticamente.” O leitor é convidado a escolher entre listas de conteúdos, totalizando 107 opções.

Folha Online disponibiliza "Em cima da hora"; Estadao.com, "Últimas notícias"; Elpais.com, "Lo último". Em todos esses exemplos, a notícia postada geralmente é apenas um breve relato de 
algo ocorrido instantes atrás. Em sua maioria, é material de agência de notícias. Essas seções funcionam como painéis informativos, que situam os leitores na atualidade de fatos que acabaram de ocorrer.

A proposta do Webjornalismo é uma mudança na perspectiva temporal, situando leitor e acontecimento num mesmo plano narrativo. Tem-se aí a ideia do dispositivo, não apenas atrelado às questões de ordem física, tais como suporte material, mas indo além, atingindo as expectativas decorrentes das potencialidades atreladas ao próprio suporte (DALMONTE, 2009).

Por fim, vale lembrar que a promessa jornalística de situar o leitor sobre a temporalidade dos fatos narrados não é nova, mas está atrelada aos desenvolvimentos tecnológicos. Exemplo dessa relação pode ser encontrado no jornal A Provincia, que começou a circular em Recife em 6 de setembro de $1872,{ }^{15}$ como órgão do Partido Liberal (NASCIMENTO, 1966, p.174). Na década de 1920, A Provincia divulgava informações baseadas nas possibilidades de circulação de conteúdos oferecidas pelo telégrafo. ${ }^{16}$ Mediante tal recurso, a captação da informação se dava de maneira mais rápida, até então dependente dos navios e outros meios de transporte, que faziam a informação circular juntamente com outras correspondências.

De maneira inusitada para a época, em 1925 A Provincia trazia na primeira página “Telegrammas", seguido dos dizeres: "(Dos nossos correspondentes)". Para dar continuidade aos assuntos, na página 3 havia a coluna "Última hora" e, para reforçar a ideia da temporalidade que se apresentava, incluía "(Pelo cabo submarino)", em alusão às potencialidades do telégrafo. Como numa estrutura autorreferente, ${ }^{17}$ o jornal pernambucano não narrava apenas as novidades, mas evidenciava também suas estratégias para oferecer a atualidade aos seus leitores.

Em 1929, A Provincia apresenta ampliado o espaço de "Telegrammas" na capa e acrescentou os dizeres: "Serviço de correspondentes especiais de A Provincia pela Western Telegraph e pelo Telegrapho Nacional." Na página 6 dava continuidade a "Telegrammas", dividindo o espaço entre "Interior", referindo-se aos estados brasileiros, e "Exterior", com notícias referentes a vários países. Todos os informes apresentados eram do dia anterior, fato de extrema relevância para as reflexões propostas por este artigo, tendo-se em vista a centralidade do conceito de tempo para a consolidação da narrativa jornalística.

\section{Referências}

AGOSTINHO, Santo. Confissões. São Paulo: Paulus, 1984.

ARISTÓTELES. Poética. São Paulo: Imprensa Nacional, 2000.

BACHELARD, Gaston. A intuição do instante. Campinas: Verus, 2007. 


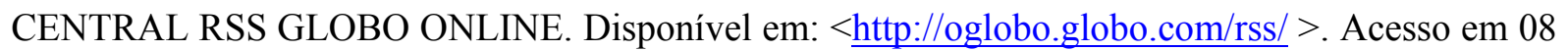
Dez. 2007.

DALMONTE, Edson Fernando. Mídia: fonte \& palanque do pensamento culturalista de Gilberto Freyre. Salvador: Edufba, 2009.

. Efeito de real e jornalismo: imagem, técnica e processos de significação. Sessões do imaginário, Porto Alegre: FAMECOS/PUCRS. n. 20, dez. 2008, p. 41-47. Disponível em: $<$ http://www.pucrs.br/famecos/pos/sessoes $>$. Acesso: 24/08/2009.

- Pensar o discurso no webjornalismo: temporalidade, paratexto e comunidades de experiência. Salvador: Edufba, 2009.

ELIAS, Norbert. Sobre o tempo. Rio de Janeiro: Zahar, 1998.

FECHINE, Ivana. Televisão e presença: uma abordagem semiótica da transmissão direta. São Paulo: Estação das Letras e Cores, 2008.

FERREIRA, Giovandro Marcus. Repensando a análise do discurso: Contribuições da hermenêutica de Paul Ricoeur. Interface, Vitória, n. 5, p. 81-94, julho 1999.

FIORIN, José Luiz. As astúcias da enunciação: as categorias de pessoa, espaço e tempo. São Paulo: Ática, 2002.

FOLHA DA MANHÃ MARÇO DE 1953. In: FOLHA DE SÃO PAULO. Primeira página. $5^{\mathrm{a}}$ Edição. São Paulo: Publifolha, 2000. p. 67.

FOLHA DA MANHÃ JANEIRO DE 1959. In: FOLHA DE SÃO PAULO. Primeira página. $5^{\mathrm{a}}$ Edição. São Paulo: Publifolha, 2000. p. 76.

FRANCISCATO, Carlos Eduardo. A fabricação do presente: como o jornalismo reformulou a experiência do tempo nas sociedades ocidentais. São Cristóvão: Editora UFS, 2005.

FREYRE, Gilberto. Casa grande \& senzala. 31. ed. Rio de Janeiro: Record, 1996a. 569 p. . Sobrados e mucambos. 9. ed. Rio de Janeiro: Record, 1996b. 758 p. . Ordem e progresso. 3. ed. Rio de Janeiro: José Olympio, 1974, 2 vol. 811 p.

GARCIN-MARROU, Isabelle. L'évenement dans l'information sur l'Irlande du Nord. Paris: Réseaux, n.76, 1996, p.47-60.

GENETTE, Gérard. Dicurso da narrativa. Lisboa: Vega Universidade, 1995.

HOHLFELDT, Antônio. As origens antigas: a comunicação e as civilizações. In: HOHLFELDT, Antônio; MARINO, Luiz C.; VEIGA FRANÇA, Vera (Org.). Teorias da comunicação. Petrópolis: Vozes, 2001.

JÖNSSON, Bodil. Dez considerações sobre o tempo. Rio de Janeiro: José Olympio, 2004.

LUHMANN, Niklas. A realidade dos meios de comunicação. São Paulo: Paulus, 2005. 
NASCIMENTO, Luiz do. A Província. História da imprensa em Pernambuco (1821-1954), v. II. Recife: Imprensa Universitária, 1966. p.174-236.

PAPA JOÃO PAULO $2^{\circ}$ MORRE AOS 84 ANOS. Folha de São Paulo Online. Disponível em: <http://www1.folha.uol.com.br/folha/mundo/ult94u82123.shtml $>$. Acesso em: 12 Nov. 2007.

RICOEUR, Paul. Tempo e narrativa. Tomo 1. Campinas, SP: Papirus, 1994.

THOMPSON, John B. A mídia e a modernidade: uma teoria social da mídia. Petrópolis: Vozes, 1998.

TRAQUINA, Nelson. Teorias do jornalismo. Vol. 1: Porque as notícias são como são. Florianópolis: Insular: 2004.

\section{NOTAS} ${ }^{1}$ A definição do que é notícia é relevante para que se aceite o discurso jornalístico como uma construção discursiva fiel
ao real. Pode-se falar, dessa forma, dos critérios para a definição do que é notícia. Segundo Hohlfeldt, "a noticiabilidade
é um conjunto de regras práticas que abrange um corpus de conhecimento profissional que, implícita explicitamente,
justifica os procedimentos operacionais e editoriais dos órgãos de comunicação em sua transformação dos
acontecimentos em narrativas jornalísticas. Reúne o conjunto de qualidades dos acontecimentos que permitem uma
construção narrativa jornalística e que os recomendam enquanto informação jornalística." (2001, p.209, grifos do
autor).

${ }^{2} \mathrm{O}$ conceito de efeito de real, originário da ideia de efeito de sentido, como proposto pela semiótica, diz respeito aos objetivos do texto em representar a realidade. A exemplo da literatura "realista", que se esmera em descrever o ambiente e o estado psicológico dos personagens, o jornalismo procura estabelecer estratégias de construção textual para estreitar os laços entre o narrado e fato reportado. Tais conexões são exploradas em Dalmonte (2008).

${ }^{3}$ Embora não se possa falar de maneira simplória desta necessidade que o jornalismo tem de falar a partir do real, algumas concepções reducionistas tentaram limitar a práxis jornalística ao que Traquina (2004, p.146-149) chama de "Teoria do espelho", numa alusão ao desejo de que o jornalismo apresente, por meio de seus relatos, apenas aquilo que é observado, sem a menor interferência do repórter, que deve anular totalmente a sua subjetividade, atingindo a total imparcialidade.

${ }^{4}$ Sendo que dois anos antes, em 04 de Outubro de 1957, a URSS havia lançado o Sputnik, fato que marca o início da exploração espacial.

${ }^{5}$ Dentre eles, pode ser destacado Gaston Bachelard que, em A intuição do instante (2007), faz uma exploração do tempo, tomando por referência as idéias de Bérgson, Roupnel e as teorias de Einstein.

A professora de física Bodil Jönsson, em Dez considerações sobre o tempo (1998, p.33), propõe uma distinção entre o tempo físico e o tempo vivido: "Creio que deveríamos considerar duas espécies de tempo e diferenciá-las: o tempo pessoal (vivido) e o tempo dos relógios (tempo atômico, para falar com mais propriedade).

Numa outra perspectiva, Nobert Elias, em Sobre o tempo (1998, p.33), aborda a percepção do tempo como resultado de uma construção social. “A percepção de eventos que se produzem 'sucedendo-se no tempo' pressupõe, com efeito, existirem no mundo seres que sejam capazes, como os homens de identificar em sua memória acontecimentos passados, e de construir mentalmente uma imagem que os associe a outros acontecimentos mais recentes, ou que estejam em curso. Em outras palavras, a percepção do tempo exige centros de perspectiva - os seres humanos - capazes de elaborar uma imagem mental em que eventos sucessivos, A, B e C, estejam presentes em conjunto, embora sejam claramente reconhecidos como não simultâneos."

${ }^{6}$ Embora nem todas as modalidades jornalísticas sejam narrativas, o editorial, os artigos, por exemplo, são dissertativoargumentativos.

${ }^{7} \mathrm{O}$ filósofo grego viveu entre 384 a 322 a.C. É incerta a data de produção de sua obra Poética.

${ }^{8}$ Aurélio Agostinho viveu entre 354 e 430, vindo a se tornar importante pensador da cristandade. As Confissões foram escritas, provavelmente, entre 397 e 398.

${ }^{9}$ Importante contribuição do pensamento acerca de uma temporalidade trina aparece na obra de Gilberto Freyre (19001987). A preocupação de Freyre com o passado, tendo em vista o presente, é expressa, por exemplo, com o conceito de tempo tríbio, que marca sua trilogia principal: Casa grande \& senzala (1996a), Sobrados e mucambos (1996b) e Ordem e progresso (1974). Estas três obras na verdade não podem ser entendidas separadamente, o que é demonstrado pelo subtítulo geral da trilogia: introdução à história da sociedade patriarcal no Brasil.

Há, em Casa grande \& senzala (1996a) e em Sobrados e mucambos (1996b), uma introdução geral ao que seria o 
tempo tríbio, mas é só em Ordem e progresso (1974) que o conceito está claramente apresentado. "O tempo do relato literário e sociológico tipicamente brasileiro parece dever corresponder a situação mais complexa, de constante entrelaçamento, na consciência do brasileiro, dos três tempos: o passado, o presente e o futuro. Pois somos um povo, mais que o anglo-americano, ligado, em nossa existência, ao passado, embora também americanamente sensível ao presente e ao futuro que, entre nós, como entre os anglo-americanos, são solicitações de tempo progressivo, utópico, messiânico associados às de espaço ainda por dominar." (FREYRE, 1974, p.XL).

O conceito de tempo tríbio apresenta a proposta de uma nova temporalidade, na qual o passado, o presente e o futuro não estariam dissociados, mas em relação direta, sendo vivenciados simultaneamente. Como Freyre (1963, p.3) define: "um passado constantemente projetado sobre o presente e sobre o futuro." Esta concepção temporal é basilar para o desenvolvimento da obra de Freyre, compreendendo-se uma renovação nas tradições da história, sociologia e antropologia (DALMONTE, 2009).

${ }^{10}$ Para análise, a autora seleciona matérias publicadas na The Times e Le Monde, publicadas à época dos atentados, em outubro de 1993, e do cessar foto do IRA, em setembro de 1994.

${ }^{11}$ A mimese I refere-se à idéia de que composição da intriga está antecipadamente presente, juntamente ao sujeito falante, numa pré-compreensão tanto do mundo quanto da ação, abrangendo suas estruturas inteligíveis, as fontes simbólicas e o caráter temporal (RICOEUR, 1994, p.88). Para Ricoeur (1994, p.101), para se entender o sentido de mimese I, é necessário dar conta de sua riqueza, enquanto imitação ou representação da ação, buscando-se "précompreender o que ocorre com o agir humano: com sua semântica, com sua simbólica, com sua temporalidade. É sobre essa pré-compreensão, comum ao poeta e a seu leitor, que se ergue a tessitura da intriga, e com ela, a mimética textual e literária." A mimese III, por seu turno, trata do mundo do leitor e de suas expectativas postas em marcha no processo de apropriação e leitura. "Significa que é bem no ouvinte ou no leitor que se conclui o percurso da mimese [...] diria que mimese III marca a intersecção entre o mundo do texto e o mundo do ouvinte ou do leitor.” (RICOEUR, 1994, p.110). Tratando do círculo hermenêutico, composto pelas três mimeses, Ferreira (1999, p.91-92), diz que: "o círculo hermenêutico, proposto por Ricoeur, põe em evidência dois processos: a transformação - a passagem da apresentação das coisas pela sua representação - e a transação ou negociação - entre o posicionamento dos sujeitos implicados na produção e reconhecimento do discurso."

${ }^{12}$ URL: < http://ultimosegundo.ig.com.br/>

${ }^{13}$ A autora refere-se ao ano de 2002.

14 “O RSS (Really Simple Syndication) é um formato de arquivo padronizado mundialmente para distribuição automática de notícias. Desenvolvido a partir da linguagem XML (eXtensible Markup Language), ele facilita o acesso dos internautas ao conteúdo atualizado no site de forma instantânea. A grande vantagem do formato, que vem se tornando cada vez mais popular, é que você não vai precisar mais procurar por uma informação de seu interesse: ao assinar uma lista RSS (também conhecida como feed), as notícias vão até você!” (CENTRAL..., 2007).

${ }^{15}$ Para uma visão completa do jornal A Provincia, consultar Luiz do NASCIMENTO. A Provincia. In: História da imprensa em Pernambuco (1821-1954). Vol. II. Recife: Imprensa Universitária, 1966. p.174-236.

16 “A partir de 1870 já havia cabos em quase todo o Sudeste Asiático, ligando a Europa à China e à Austrália. Em seguida vieram os cabos entre a Europa e a América do Sul e ao longo da costa da África. Por volta de 1900, aproximadamente 190.000 milhas de cabos submarinos tinham sido instaladas ao redor do mundo." (THOMPSON, 1998, p. 138).

17 Luhmann (2005, p.26-33) contrasta duas modalidades de construção discursiva: heterorreferência e autorreferência. Por heterorreferência o autor entende o modo da mídia falar sobre o mundo, relatar questões de outras esferas ou as formas de construção da realidade. A autorreferência, por sua vez, diz respeito ao processo de narrar a si, enquanto narra o mundo, ou a descrição da realidade de sua construção da realidade.

Artigo recebido em 10/2009. Aprovado em 01/2010. 